ried thus by the mother-who gives them no other attention than an occasional brushing to keep them free from particles of dirt-for a fortnight, when they are ready to hatch.

In the meantime, however, some remarkable changes have been taking place. If under the dissecting microcope we tear open an egg which is but a day old the differentiation of its organization can be seen making its first appearance. That mysterious transformation, lue to those unfathomed forces which cause the cells to assume their predetermined arrangement, has jus taken place. Nearly a week later examination of on of the spherical units will show that the yolk comprises nearly half the bulk, while the remainder of the eg. content reveals the dim outlines of the nascent larva. Each succeeding day the embryo is marked by a gradual but very definite change. Finally the tiny animal ac quires a segmented hindbody, a large tail fin, and pair of unstalked eyes. A more dissimilar offspring from the crawling adult could hardly be imagined; for the muscular ringed belly and broad tail singularly adapt it at this stage to a roving life at any depth.

The moment for hatching is always sionalized some hours before by a restless activity on the part of the larvae, and by their apparent efforts to burst the double envelopes which confine them. Suddenly the walls of an egg will split lengthwise and a wriggling youngster emerges through the rent. It has no time to linger, as it is caught in the respiratory currents of the mothe and sent hustling away. A common impulse then seem to animate the brood, and within a few hours the re-
Nevertheless, some reliance may be placed in the data afforded by comparative anatomy when attempting to reconstruct the phylogeny of a species, and from these data it may reasonably be assumed that the ancient orbears of the hermit crab possessed a segmented abdomen equipped with specialized appendages for swimming. From this it follows as a corollary that it was a rover of the open sea. That it later frequented the floor of the ocean is very probable. The present habits of other higher crustaceans-such as the lobster and kindred types-point unerringly to this conclusion.

But why did the primitive non-shell-bearing hermi crab forsake the open reaches to become a dweller of the shore waters? The answer to this question admits only two possible inferences. It was forced to seek this habitat for reasons either of hunger or of safety. I think the first mentioned may safely be dismissed as wanting in plausibility. There is no good reason to believe that food material suitable for these animals did not always thrive in as great abundance in the outer. regions as well as contiguous to the shores. In regard to the remaining factor, I will say at once that this latter seems to be the true and only cause. It was because of the appearance on the scene of a new and powerful enemy. This enemy was the first verte brate-the mailed fish. For it must be remembered that until that time the crustaceans alone held dominion over the floor of the sea, and the greatest enemy of the crustaceans were themselves-the larger preying upon the smaller. But with the advent of these new marin terrors came a change. The extinction of the hermit and experiment, covering a period of ten ycars, he has at last discovered a process which has opened up a new industry. When we consider that there are approximately ten thousand wood and cardboard box manufacturers in the United States, and that the annual output of the box trade runs into the millions, we must realize how important is this new composition, which is used largely in the production of boxes.

It is an interesting experience to watch the production of these boxes, really beautiful in desion and finish, from the mixing room to the painting room, when the finishing touches are applied by skilled hands. O course, the mixing room holds the secrets of the process. We know that ashes and sawdust--the ashes of the two main incredients of the composition. To these wo constituents chemicals are added; the whole mixture is worked together thoroughly and rubbed by han through a large sieve; and the resulting rather coarse dry powder is then ready for the presses.

ine operation of the presses is an important factor in the cheapness of the whole process. There a re four presses in Dr. Jaeger's factory. 'Two of them are for the making of the bottom parts of the boxes; and two of them, by means of elaborately designed bronze dies. impress upon the covers of the boxes designs ancien or modern, Roman, Greek, Egyptian, Gothic, Moresque. or of the Renaissance period. The powder from the mixing room is inserted in little boxes under the presses; the presses are lowered for a period of about three minutes; the powder bakes like bread, turns a
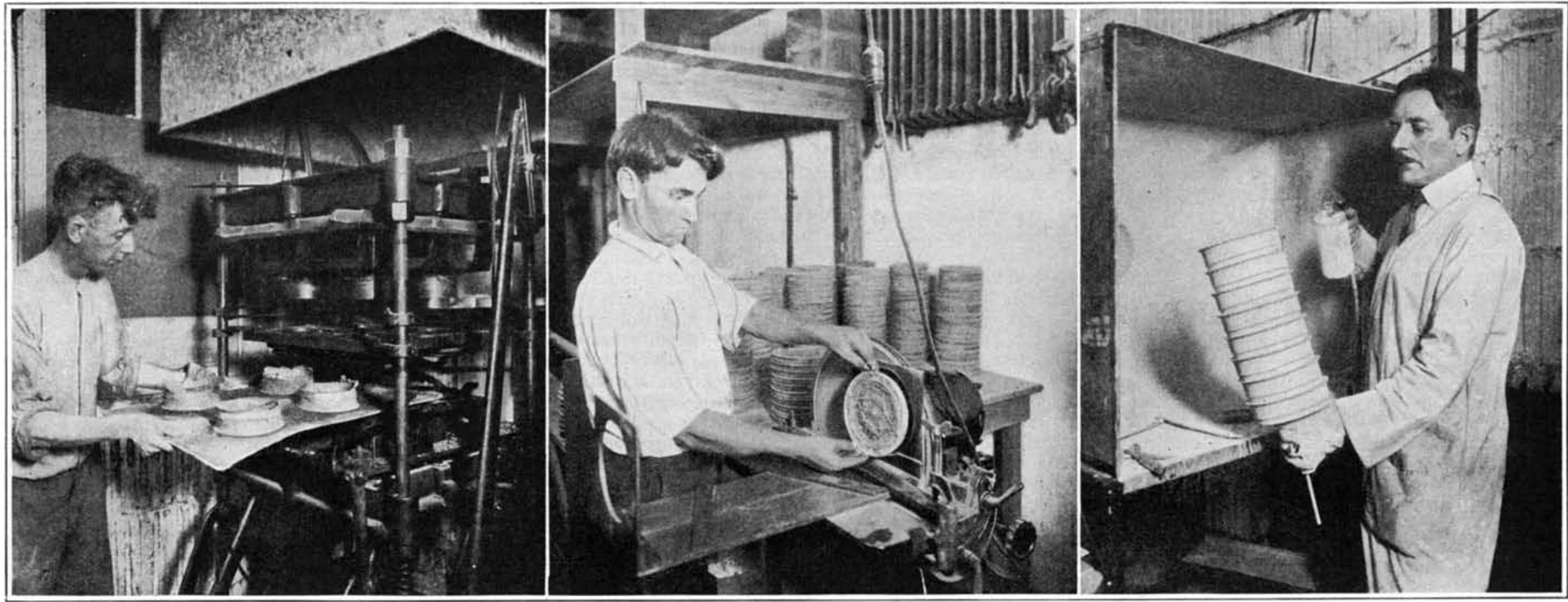

Left: The finished box being taken out of the press. Center: All manner of fancy designs can be achieved in these boxes. Right: A row of finished boxes being sprayed

Making boxes from a chemical composition obtained from ashes and sawdust

mainder of the children abandon forever the precincts of the maternal shell. The mother then detaches the swaddling clothes still adhering to her appendages, and sorm following the departure of her young she sends bag and bagoage flying after.

Thenceforth each little hermit crab pursues its uncertain fortunes alone. After a lapse of nearly two month. - during which it molts not less than four times, each time increasing in size and acquiring a more adult-like form-it settles to the bottom and finds a tiny shell.

Such is the manner in which the hermit crab is ushered into the world. A rapid survey of its future shows that before the winter gales have forced it int the deeper waters to pass a semi-dormant existence it has molted once more and has now attained the length of a quarter of an inch. The following summer will find it considerably larger, provided it will have had plenty of food, and by the end of the third year it will have arrived at sexual maturity; whereupon it will begin to take notice of its fellows, both male and female. From this time onward its brawlings and lovemakings will continue until the end of five years, when, realizin that the business of life is done, it crawls under some sheltering frond of seaweed and dies.

Now, if one accepts the evolutionists' theory that the embryological forms of an animal tend to recapitulat the evolution of the species, there is more, then, than a mere hint in the foregoing that the hermit crab did not always require a shell for its protection. As the fossil remains of crustaceans have been so meager, there is now, of course, no certain means of determinin the true appearance of the hermit crab's ancestor. crab was threatened. In fact, the actual disappearance of hundreds of group

The case then clears itself. With the ever constant menace hovering over it for generations after generations, the hermit crab was driven to the shallowe waters and into any place which afforded a shelter. In the great abundance of shells in this neighborhood it found an admirable haven of refuge. Later it found it quite convenient to carry the shell with it, instead of venturing forth unprotected in search of food. And it was not until the disappearance of these monstrous enemies that certain of its shell-bearing kin wandered back into the deeper waters.

But this change to a fugitive life also brought a change in its diet, and ages of an abnormal adaptation have changed the structure and functions of its body. Wrom the predatory life of a rover and a freebooter $i$ has descended to the life of a scavenger. His belly, once an entity of strength, is now a feeble mass of pulp. In a word, the hermit crab is a degenerate.

\section{Ashes and Sawdust the Basis of a New Industry}

By C. M. Lewi

$\mathrm{N}$ these days of large-scale production and largescale waste in American industries, it has remaine for Dr. Christian Jaeger to utilize two of our most easily obtained waste materials, sawdust and ashes, in a re markable chemical composition which is a substitute for cardboard and wood. After long and patient study delectable, creamy brown, gives off a pungent odor; the presses are lifted; and out come the boxes, complete in shape and design from a single operation. One of ur photographs shows a close-up of a tray of boxe fresh from the presses. The rough edges are smoothed off on rotary emery wheels; then the boxes go to the painting room.

The discovery of a paint which could be applied to this composition was not made until after a good many fruitless experiments on the part of Dr. Jaeger. At first, the paint refused to stick to the surface; it curled up and flaked off At last, after about two years, Dr. Jaeger produced a paint that could be applied smoothly and would give an even, glossy finish. The first coat of paint is applied by hand. One of the virtues of Dr. Jaeger's paint is its drying quality. No drying rooms are necessary ; almost as soon as the first coat is applied the boxes are passed on to the workmen who handle the air brushes and finish them with delicate tints or with ivory, ebony, bronze, silver or gold effects. The finished boxes are light in weight, washable sanitary and non-poisonous. They are as fire-proof a asbestos, waterproof, and can be made of any deore of texture or flexibility, either as pliable as cardboard, as hard as oak, or as tough as metal. They are very cheap; a pound of the substance, from which about hree boxes can be made, costs not more than five cents. Climatic changes will not affect them; they neither shrink nor expand. They can be plated in genuine ronze, silver or gold, or finished in the process with a surface of chemically prepared silk or satin, real or imitation plush or velvet. 


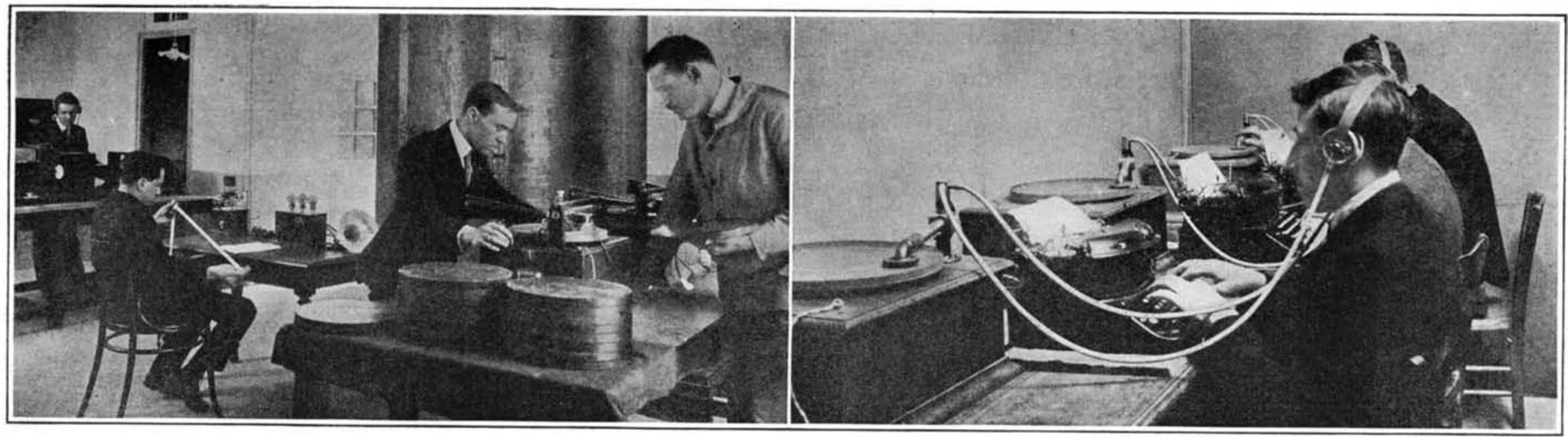

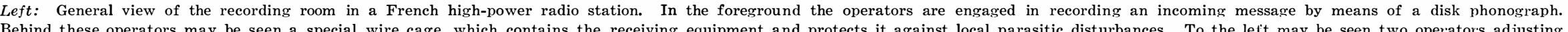

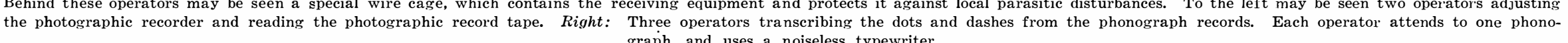

Capturing the elusive dots and dashes of radio on phonograph records and photograpic tape for subsequent transcription

\section{Speeding Up Radio}

New Methods Employed for the Automatic Reception of Radio Telegraph Dots and Dashes By Francis P. Mann

$\mathrm{T}_{\text {radio telegraph }}^{\mathrm{HE} \text { capacity of }}$ radio telegraph
stations is to be in creased to a considerable extent in the near future by the use of rapid methods for receiving the messages. The efforts in this direction which have been made by one of the largest French radio companies are now meeting with great
success. This firm has been very active in the construction of wireless stations, one of the most recent being the great station of La Doua, at Lyons, which is now working with the United States. This station has already been described in our columns, so that we will confine our present efforts to a brief account of he methods and apparatus which are employed for recording the messages at high speeds.

The phonograph method is employed for taking down messages at speeds which are considerably above the usual rates, this speed being in all cases above 25 words per minute and may reach as high as 100 to 150 words. But it is evident that messages with the dot and dash system cannot be read at such high speeds on the telephone by the operators of the station. The phonograph can, however, be called upon to take down the messages at these rates, and by means of the new apparatus the signals are now recorded upon the phonograph without difficulty. A phonograph of the customary disk type is employed for this purpose, making necessary certain slight changes in the equipment, such as are required to adapt it to radio service, all that is necessary being to mount the receiving telephone in the place of the usual phonograph recording diaphragm, the telephone diaphragm being provided with a stylus for producing the record on the disk.

It is found that the phonograph record is still quite satisfactory when the applaratus is working at 150 words per ninute. When the disk has received the telegraph message, it is transferred to a second device which serves to reproduce the sounds in the usual manner, but the record type of phonograph is of a somewhat different design, and is designed to operate at slower speed in order to enable the operator to read the messages.

One of our illustrations shows in the foreground the high-speed phonographs which are employed to take down the messages, while in another view will be observed the slowspeed apparatus used for reproducing purposes only, with an operator for each phonograph taking down the messages on a noiseless typewriter as fast as he is able to write. In order that the sound shall not be of too low a pitch when running the phonograph at reduced speed

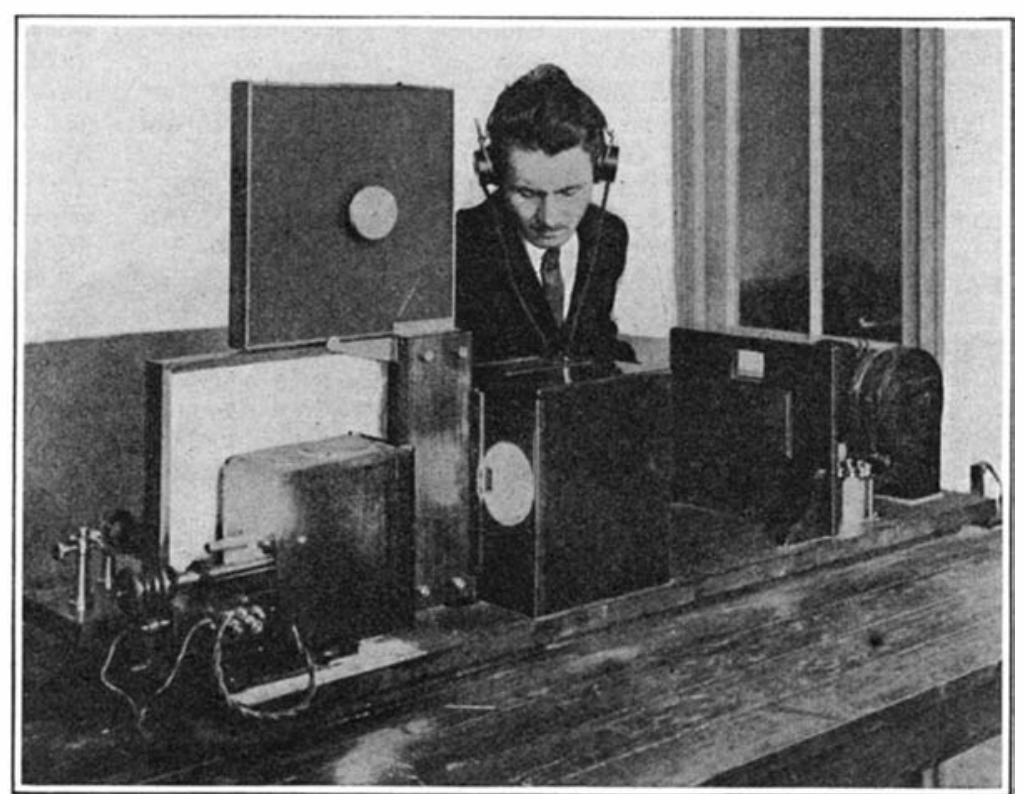

Photographic recorder working at a speed of 200 words per minute. The operator, wearing the 'phones, hears the signals and can adjust the recorder accordingly adapted to swing under the action of the radio impulse forming the signals. the current at the receiving end being amplified to $\mathrm{th}$ proper degree by the use of the usual amplifying devices. The duration and a mou $\mathrm{t}$ of the swing of the mirror transcribed message below each dot-dash character

for receiving the messages, the radio receiving apparatus is regulated, in case the system of continuous waves is employed, in such manner as to provide a high pitch for the original message, so that the pitch "an afterwards be reduced without being too slow to arry out the receiving operations to good advantage. can be renched by making use of the photographic method, and by the use of improved apparatus recently brought out by the French firm it is possible to operate at speeds which can handle up to 500 words per minute siges than the phonograph system, and the new photographic apparatus is not of an unduly complicated nature. Indeed, it is so designed that all the operation. can be carried out in a very simple manner and by persons having no very special skill.

The photographic recorder is based on the use of a alvanometer containing a small mirror which is

will correspond to the dot and dash signals, while the mirror reflects a beam of light on to a strip of sensitive paper tape which is caused to unroll at a greater or less speed, according to circumstances. The beam of light thus traces the message on the strip. The result is that the messace will appear in the form of dots and dashes, as shown in one of our illustrations, when the strip is developed by the usual photographic process. No difficulty is experienced in taking down messages at the rate of 500 words per minute. It should be remarked that such messages could not be read by a station which is not provided with the photographic receivin $\alpha$ devices.

The new system will be valuable as affording a method of considerably increasing the capacity of radio vations, and the method is, in fact, comparable to automatic telegraphy. The developing, fixing, washins and drying of the photograplic strip are curried out automatically by means of an improved device which jerforms all these operations within a very short time. It is now found possible to use the same photographic strip to receive messages sent out by two different stations at the same time, or by the same station sending two simultaneous messages (in fact, several messages can be sent) on the new multiplex system. In the present devices, two messages can be taken down at the same time and upon the same photographic strip. When the latter is completely finished, it can be read in the same way as an ordinary telegraph recorder tape.

The dot and dash signals are very sharp and clear, allowing the messages to be rapidly read off. It should be remarked that the dots and dashes being received can even be heard in the telephone receivers, even though they are too rapid to be read, but this at least affords a good means for adjusting the recording apparatus. The new devices have all the sensitiveness of laboratory instruments and at the same time are very simple and strong, being adapted for actual use in radio stations.

The photographic recording apparatus will be observed in the background of one of our illustrations, which shows the various devices in a French radio station. 